\title{
TIEMPO Y NARRADOR EN EL LAZARILLO (EPISODIO DEL CIEGO)
}

Los trabajos que sobre el Lazarillo de Tormes se han publicado en los últimos veinte años revelan un creciente interés por su técnica narrativa. Es un campo extenso, en el que mucho queda por hacer. Dos de sus aspectos me parecen particularmente apasionantes: el tiempo y el narrador. Ambos fueron abordados por Claudio Guillén en su bien conocido artículo de $1957^{1}$. A Guillén le importó mostrar que el tiempo "cronológico" se subordina en esta obra al tiempo psicológico, que "lo narrado queda referido al ser del narrador" (p. 271). Mi enfoque será un tanto distinto: me interesa observar de cerca cómo se maneja el tiempo dentro del texto y -porque las dos facetas están intimamente relacionadasqué formas y qué funciones adopta en él la presencia del narrador. Hay otros dos aspectos concomitantes que importa observar: el manejo del espacio y el uso del estilo directo. Dada esta multiplicidad de facetas, me limitaré por ahora a la exploración del Tratado Primero. El análisis habrá de conducir a ciertas conclusiones sobre la construcción de ese capítulo, principalmente del episodio del ciego, y aquí mi trabajo empalma con las investigaciones de Fernando Lázaro Carreter ${ }^{2}$.

\section{EL TIEMPO}

El instrumental teórico de que me he servido para analizar el manejo del tiempo en el primer episodio del Lazarillo es muy sim-

I Claudio Guillén, "La disposición temporal del Lazarillo de Tormes". $H R, 25$ (1957), 264-279. Cf. también la Introducción de Guillén a su edición de Lazarillo de Tormes and El Abencerraje, New York, 1966.

¿F. Lazaro Carreter, "Construcción y sentido del Lazarillo de Tormes", en su libro "Lazarillo de Tormes" en la picaresca, Madid, 1972 [abrevio: Fernando Lázaro]. El libro de CHARLEs MINouet, Recherches sur les structures narratives dans le "Lazarillo de Tormes", Paris, 1970, no tiene relación directa con mi análisis; estudia, con enfoque estructuralista, los temas principales y su manifestación en el texto, las relaciones de Lázaro con el mundo y algunos "faits de structure". 
ple, puesto que el texto mismo sólo ofrece, básicamente, dos modalidades: el relato "iterativo-durativo" y el relato "escénico"; a ellas se añade el relato "sumario", que aparece en las páginas anteriores al episodio del ciego. Convendrá, antes que nada, situar estos tipos de relato dentro del panorama conceptual elaborado por los teóri$\cos$ de la literatura que se han ocupado del tiempo narrativo y explicar brevemente cómo concibo tales conceptos aquí.

Estudiar el funcionamiento del tiempo en una obra narrativa significa analizar las relaciones que se dan entre el tiempo de la historia, o sea, la "temporalidad propia del universo evocado" 3 , y el tiempo del relato ${ }^{4}$, o sea, la temporalidad que opera dentro del texto. Para entender esas relaciones se han venido usando, desde la clásica obra de Percy Lubbock ${ }^{5}$, dos conceptos fundamentales, que se oponen uno al otro:

\section{sum mary / scene.}

El summary (sommaire: Genette, resumen: Ducrot-Todorov) es, en la compacta definición de Friedman, "un relato generalizado [y sucesivo] de una serie de eventos ocurridos en un lapso temporal más o menos extenso y en sitios diversos", mientras que la scene (scène, escena) surge cuando "hacen su aparición los detalles específicos, continuos y sucesivos de tiempo, lugar, acción, personajes y diálogo" "Estos son los dos tipos de relato que alternan normal-

3 O. Ducrot y T. Todorov, Diccionario enciclopédico de las ciencias del lenguaje, Buenos Aires, 1974, p. 359. Además de "tiempo de la historia", los autores registran las designaciones "tiempo de la ficción", "tiempo narrado" (traducción de la erzählte Zeit de Günther Müller), "tiempo representado".

4 O "tiempo de la escritura", "tiempo de la narración" (de Erzählzeit) o "tiempo relatante" (loc. cit.). Para el tema que nos ocupa cf. EBerhard Läмmert, Bauformen des Erzählens, 6a ed., Stuttgart, 1975; Wayne C. Booth, The rhetoric of fiction, $10^{\mathrm{a}}$ ed., Chicago, 1973, y sobre todo GÉrard Genette, "Discours du récit. Essai de méthode", en su libro Figures III, Paris, 1972 [abrevio: Genette]. Las tres obras incluyen extensa bibliografía.

5 The crafi of fiction, London, 1921.

6 Norman Friedman, "Point of view in fiction: the development of a criticai concept", PMLA, 70 (1955), 1160-1184; la cita, p. 1169: "Summary narrative is a generalized account or report of a series of events covering some extended period and variety of locales...; inmediate scene emerges as soon as the specific, continuous and successive details of time, place, action, character and dialogue begin to appear". Cf. infra, nota 8. Lubbock empleó, con el mismo sentido de summary / scene, las oposiciones panoramic presentation / scenic presentation y pictuse / drama, pictorial / dramatic, etc. Por cierto que ya treinta años antes, en 1891, había lanzado Otto Ludwig la pareja "relato propiamente dicho" / "relato escénico" (cf. Ducrot-Todorov, op. cit., p. 369). Otra pareja de contrarios que se maneja frecuentemente como equivalente de "resumen" / "escena", es telling / showing. Cf. W. C. 
mente en la novela moderna. Pero al estudiar la obra de Proust se encontró Gérard Genette con la imposibilidad de encuadrarla en ese esquema y emprendió un análisis más fino de las categorías temporales que pueden operar en la literatura narrativa. No sólo importan las relaciones de duración (o rapidez), que son las que se dan en la pareja "resumen" / "escena", sino también las de orden y las de frecuencia. Entre estas ú'timas hay dos tipos fundamentales:

el relato i t e $\mathrm{r}$ a $\mathrm{t}$ i v o, que cuenta una vez lo que en la historia ha ocurrido $n$ veces, $y$

el relato s $\mathrm{i} n \mathrm{~g} \mathrm{u} 1$ a $\mathrm{t}$ i vo (es término de Genette), en el cual se cuenta una vez lo que ocurrió una vez ${ }^{7}$.

En la obra de Proust el ritmo del relato descansa precisamente en la alternancia de estas dos modalidades (Genette, p. 170). Tres y medio siglos antes, el autor del Lazarillo habia escrito de la misma manera las partes más importantes de su libro. Al analizarlo me he llegado a preountar si el factor determinante en la pareja "iterativo/singulativo" es realmente la "frecuencia". Por una parte, más que de relato iterativo habría que hablar de relato iterativo-durativo (como lo hace Lämmert), pues tiene esas dos modalidades, a menudo difíciles de distinguir, la segunda de las cuales no puede entrar en un sistema basado en la repetición o no repetición de los hechos. Por otra parte, tanto en Proust como en el Lazarillo, el relato singulativo es siempre un relato "escénico", o sea, toda una secuencia de "hechos" singulativos.

El relato iterativo-durativo tiene características muy especiales. Constituye una síntesis, pero no como la del resumen, el cual, respetando la sucesión de los hechos en la historia, los condensa. En el iterativo - lo llamaré así para simplificar- el tiempo no se recorre de un extremo al otro: se contempla en su conjunto, como una sola unidad de rasgos comunes, los cuales suelen agruparse en subconjuntos "por medio de una especie de clasificación paradigmática de los acontecimientos que la componen" (Genette, p. 150). Es una síntesis a la cual llega el escritor a través de un proceso de abstracción, de generalización. El iterativo está en cierto modo al margen del tiempo. Normalmente tiene límites diacrónicos y una extensión temporal dentro del relato (lo que Genette llama, respectivamente, détermination y extension), pero "la diacronía real (por definición, singulativa) sólo interviene para marcar los límites de la serie..., sin que ésta quede marcada realmente por el

Bootr, op. cit., passim. Bien ha dicho Todorov que "el defecto de estas oposiciones es evidente: cada una de ellas abarca varias categorías independientes" ( Ducrot-Todorov, op. cit., p. 370).

7 GenetTe, pp. 145 ss. 
transcurso del tiempo" (Genette, p. 167). La naturaleza intrínseca del iterativo es tan atemporal como la de la descripción, con la cual tiene, por cierto, mucho en común (cf. ibid., p. 148) .

Frente al relato iterativo, el singulativo (escénico) se refiere a hechos particulares, únicos, cada uno de los cuales se ha producido en un punto definido de la historia, dentro de una cadena diacrónica de hechos. La oposición entre los dos tipos de relato parece residir, pues, en el carácter generalizador y atemporal del relato iterativo frente al carácter particularizador y temporal del singulativo. $\mathrm{O}$ sea:

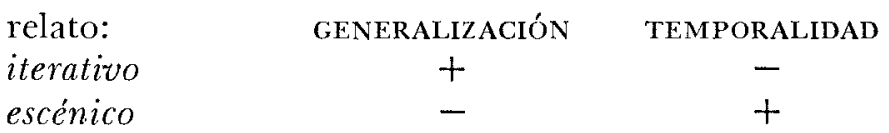

Dentro de este esquema, el relato sumario (resumen) resulta ser una variante (un alomorfo) del relato escénico, puesto que también se refiere a hechos únicos que se suceden en el tiempo ${ }^{8}$. Lo que distingue a los dos tipos es la "rapidez" (vitesse) del relato, o sea, la clase de relaciones que se establecen entre la duración de la historia, medida con los conceptos cronológicos habituales (años, meses, días, horas, etc.), y la amplitud del texto, medida a base de páginas y líneas (ibid., p. 123).

Si en la novela moderna hay, fundamentalmente, una alternancia entre el relato sumario y el escénico, en el Lazarillo de Tormes, considerado en su conjunto, el resumen se turna con la alternancia relato iterativo-relato escénico, que es la que determina el ritmo narrativo de las secciones más desarrolladas de la obra (episodios del ciego, del clérigo, del escudero y del buldero) .

\section{EL NARRADOR}

"Las categorías del tiempo y de la persona están estrechamente vinculadas. La existencia de una visión (de un narrador) significa al mismo tiempo la existencia de una temporalidad de la escritura... El narrador nunca puede estar totalmente ausente" ". En la

8 Disiento de Friedman cuando dice (art. cit., p. 1169) que la principal diferencia entre la narración resumida y la escena es "of the general-particular type" y cuando, consiguientemente, llama "relato generalizado" al sumario.

9 Ducrot-Todorov, op. cit., pp. 362 s. Cf. Booth, op. cit., pp. 154 s.: "The contrast between scene and summary, between showing and telling, is likely to be of little use until we specify the kind of narrator who is providing the scene or the summary". El libro de Booth ha hecho mucho para desvanecer el prejuiciado ideal de la novela como relato impersonal en el cual las cosas deben "contarse a sí mismas". Su tesis central es que el narrador "is always 
novela autobiográfica el narrador es un "yo" (ficticio) que, desde el presente (también ficticio) en que pone por escrito sus recuerdos, contempla y valora las acciones y vivencias de ese otro "yo" que es su protagonista. La vida de éste se desarrolla en un pasado que se va acercando al presente del narrador y que converge con él al final; ya sabemos que ese pasado, el pasado de la historia, funciona a su vez como un presente, pese a los tiempos verbales y a los adverbios. Es característico del relato en primera persona el que "sobre el presente de la acción se extienda un presente del narrador, aún más inmediato, desde el cual el escritor comenta los sucesos narrados, aclarándolos, reforzándolos o criticándolos"; son palabras de Eberhard Lämmert, quien, por otra parte, reconoce que el yo-narrador "no está todo el tiempo por encima del ficticio esquema espacio-temporal de su narración": "Como actor e intermediario lleva una doble existencia, sugiriendo al lector la tensión y la espera del futuro que vive realmente el yo actuante, pero también, en otros pasajes, hablando directamente al lector como un yo narrante". En la novela autobiográfica "cambian continuamente las perspectivas del yo que vive y del que relata" ${ }^{10}$.

Esto es, ni más ni menos, lo que ocurre en el Lazarillo de Tormes. El Lázaro narrador juega a aparecer, desaparecer y volver a aparecer en el tablado de su texto. Es un personaje que está ahí y no está; que de pronto se hace presente junto a su hermano menor, el Lázaro protagonista, para en seguida esconderse detrás o dentro de él. Las marcas visibles de su presencia son de muy diversa índole, y su visibilidad es mayor o menor. Quizá la señal más patente es la alocución al destinatario, a ese personaje fantasma llamado Vuestra Merced. Otra bien clara es la mención expresa del presente desde el cual escribe (el "hoy") y el establecimiento, por otros medios, de la perspectiva temporal que ese presente le impone (digamos, la frase “que jamás yo vi ni ver espero", 158) ${ }^{11}$.

present" y que su presencia es "evident to anyone who knows how to look for it"; el narador (al que aquí llama "autor") "can to some cxtent choose his disguises, lie can never choose to disappear" (p. 20).

10 LÄMMERT, op. cil., p. 45: "die Gegenwart der Handlung wird ïberbaut durch eine noch unmittelbarere Erzählergegenwart, aus der heraus der Dichter erläuternd, bekräftigend oder kritisierend das erzählte Geschehen kommentiert"; p. 72: "Denn es ist keineswegs so, dass der Ich-Erzähler dauernd über dem fiktiven Zeit-Raum-Schema seiner Erzählung stünde, wie Käte Hamburger annimmt. Er führt als Akteur und Vermittler eine Doppelexistenz, indem er dem Leser die reale Spannung und Zukunftserwartung des handelnden Ich suggeriert und ihn an anderen Stellen wieder als erzählendes Ich direkt anspricht"; "[es] wechseln die Perspektiven des erlebenden und des erzählenden Ich ständig".

11 Utilizo la reciente edición de Alberto Blecua, Madrid, 1972 (Clásicos Castalia, 58), la cual, además de ser excelente, tiene la ventaja de estar al 
Las alusiones a su actividad de narrador ("por no ser prolijo dejo de contar muchas cosas...", I, 106) lo hacen pasar también a un primer plano; en menor escala, las alusiones a pasajes anteriores ("como he contado", II, 113) o posteriores de su texto.

El Lázaro protagonista es, como sabemos, un gran reflexionador, y su narrador evoca continuamente esas meditaciones ("dije entre mí: "Verdad dice éste, que me cumple avivar el ojo..., pues soy solo»", I, 96). A veces le gusta inmiscuirse en ellas, como cuando, a propósito de los insomnios en el episodio del clérigo, da primero la interpretación del muchacho: "echábalo al no comer", y luego la suya: "y ansí sería, porque, cierto, en aquel tiempo no me debían de quitar el sueño los cuidados de el rey de Francia” (II, 123).

Pero aparte de esto, el narrador se permite introducir una serie de reflexiones por su cuenta y riesgo (como el famoso pasaje del comienzo, I, 94: "No nos maravillemos de un clérigo ni fraile porque el uno hurta, etc.") y aducir máximas para explicar los hechos ("Como la necesidad sea tan gran maestra. ..; me era luz la hambre, pues dicen que el ingenio con ella se avisa, etc.", II, 122). La presencia del narrador también es hasta cierto punto discernible en la actitud continua y enfáticamente valorativa, en los característicos adjetivos que tiñen de afectividad a los seres y a las cosas, en los posesivos que entablan emotivas relaciones de pertenencia ("su puerta", "mi calle"). Pero ya en estos casos el narrador está, de hecho, tan identificado con su personaje, que las valoraciones reflejan también los estados de ánimo del muchacho. Hay en la obra muchos momentos en los que la evocación es tan intensa, que el narrador, olvidado de sí mismo, se hace transparente, desaparece.

Estos distintos grados de visibilidad del narrador, desde la presencia total hasta la (aparente) ausencia total, están relacionados con las modalidades que asume el tiempo en el relato. De antemano podríamos esperar una mayor presencia en el relato sumario $y$ en el iterativo que en el relato escénico ${ }^{12}$. Pero esto vamos a explorarlo directamente en el texto del Tratado Primero.

alcance de todos. Los números arábigos remiten a la página, los romanos, al tratado. Menudean en el Lazarillo las referencias al pasado que revelan una visión global, sólo obtenible descle el presente del narrador: "descle ahí adelante" (102), "todo el tiempo que con el veví" (116), etc.

12 Hablando de la escena dice GENETIE, p. 187: "Les facteurs mimétiques proprement textuels se ramènent... à ces cleux données...: la quantité de l'information narrative (récit plus développé, ou plus détaillé) et l'absence (ou présence minimale) de l'informateur, c'est-à-dire du narrateur... D'où ces deux préceptes cardinaux du showing: la domiuance jamesienne de la scène (récit détaillé) et la transparence... du narrateur ... La quantité d'information et la présence de l'informateur sont en raison inverse..." (este último subrayado es mío). 


\section{LA INTRODUCCIÓN Y LA TRANSICIÓN}

El episodio del ciego no ocupa, como los del clérigo, el escudero y el buldero, todo un tratado, sino que comparte el primer tratado con una introducción que relata los antecedentes del protagonista, hasta el momento en que ya es "buen mozuelo" (91-95) y con una breve transición que refiere la aparición del ciego, su "contratación" de Lazarillo y la despedida de la madre (95-96).

La primera unidad constituye un rápido resumen: unos doce años condensados en cinco paginitas, con una elipsis al comienzo (se salta del nacimiento de Lázaro al momento en que tiene ocho años) y un desarrollo precipitado de los hechos hasta antes del encuentro con el ciego. De las dos precisiones cronológicas que nos da el texto -el padre, molinero "más de quince años" y "siendo yo niño de ocho años" (92) - sólo la segunda es pertinente (psicológicamente) para la historia, y ninguna tiene una función en el tiempo del relato, puesto que el paso del tiempo no se volverá a marcar con referencias de este tipo. La secuencia misma de los hechos y algunas indicaciones vagas ("continuando la posada y conversación. ..", 93; "se acabó de criar mi hermanico. ..", 95) son las que nos sugieren el transcurso del tiempo, sin que podamos nunca precisarlo ${ }^{13}$. En la parte central de la introducción (93) el tiempo se detiene un instante con un relato iterativo que habla del negro, de su hijito y de las reacciones de Lázaro frente a los dos.

El narrador, que por primera vez se ha presentado ante nosotros, junto con Vuestra Merced, en el último párrafo del Prólogo, reaparece al lado de éste en la primera línea del tratado I: "Pues sepa Vuestra Merced ante todas cosas que a mí llaman Lázaro de Tormes" (91). Luego permanece en el escenario, haciéndose visible con su uso del presente verbal ("me puedo decir nascido en el río", "espero en Dios", 92), con su perspectiva temporal ("Yo, aunque bien mochacho...", 94), sus referencias al acto mismo de la escritura ("acuérdome", 93; "probósele cuanto digo", 94), su reflexión moral ("No nos maravillemos...", 94) y, finalmente, con su interpretación y valoración de hechos y personas ("un pobre esclavo", "el lastimado Zaide", "la triste") .

En el momento en que aparece el ciego el narrador hace mutis. El pasaje de transición adquiere así un carácter distinto. El relato sigue siendo sumario, aunque menos rápido y sin mezcla de itera-

I3 Sobre la cronología interna del Lazarillo, cf. Guillén, art. cit., pp. 273. 275; M. Batalllon, La vie de Lazarillo de Tormes, Paris, 1958, pp. 39 s.; R. S. Wiluis, HR, 27 (1959), p. 270 y nota; F. Rico, Introducción a La novela picaresca española, t. 1, Barcelona, 1967, pp. x-xi [en adelante abrevio Rico 1967]. 
tivo, pero ahora surge un nuevo elemento: el acto de hablar comienza a contar como factor activo de la peripecia. Se instaura gradualmente, pasando del estilo indirecto ("mi madre... me encomendó a él diciéndole cómo era hijo de un buen hombre, etc.", 95) a la breve y solemne alocución de la madre (" "Hijo, ya sé que no te veré más...»", 96), con la cual termina la fase de transición.

La transición no sólo se da, pues, en el nivel del contenido, sino también en el de la técnica narrativa. Lo que sigue será una escena. El autor la prepara aquí con varios recursos específicos: con la introducción del estilo directo y la "supresión" del narrador, pero además con un nuevo manejo del tiempo y del espacio. De pronto incorpora una indicación temporal - "Como estuvimos en Salamanca algunos dias", 95-, que contrasta con las alusiones anteriores (siempre vagas y referidas a tajadas de tiempo más o menos grandes) y señala el tránsito a un tempo más lento. Además logra una especie de inmovilidad del espacio, que a su vez se contrapone al manejo del espacio en la parte introductoria. En ésta los personajes han estado en continuo movimiento: del molino a orillas del Tormes el padre parte a la prisión y luego a la guerra; la madre y el hijo, a "una casilla" en la ciudad; sigue luego un ir y venir de la madre y del negro entre esa casa y las caballerizas del comendador de la Magdalena; finalmente, el paso de la madre y los niños al "mesón de la Solana", donde se produce el encuentro con el ciego. Y no hay más referencia al espacio. Hemos de suponer que después Lázaro recorre con su "nuevo y viejo amo" las calles de Salamanca, pero el texto no lo dice.

\section{LA PRIMERA ESCENA}

El episodio del ciego comienza con una escena, y ésta con tres referencias pormenorizadas al movimiento por el espacio: "Y así me fui para mi amo, que esperándome estaba. Salimos de Sala manca, y llegando al puente..." (96). Ahí se detienen. Estamos en un punto fijo. La escena es muy breve, tan breve en el tiempo de la historia como en la amplitud del texto (la indicación "más de tres días me duró el dolor" se sale de la escena: es, en el vocabulario de Genette, una prolepsis). Pero en esas catorce líneas se dan, como en miniatura, todos los elementos necesarios para crear un efecto de inmediatez, para hacer visible y también audible lo que ocurre: el lenguaje directo, que ahora es familiar y espontáneo; el desmenuzamiento de la acción en pequeños movimientos.

Salvo por el uso del presente al principio ("está... un animal de piedra, que casi tiene forma de toro", 96), el narrador no inter- 
viene. No es él, sino su protagonista, quien hace la reflexión, fundamental, a que conduce la experiencia del golpe: la conciencia que Lázaro tiene de su brusco paso a la soledad y al abandono es parte de la historia, del "presente de la acción". Quizá fuera la importancia de esta experiencia la que llevó al autor a plasmarla en un relato escénico, en la primera verdadera escena de la obra ${ }^{14}$; pero para ello había también razones de tipo estructural, como luego veremos.

\section{EL REl.ato iterativo}

En seguida se inician las andanzas de Lázaro con el ciego -“comenzamos nuestro camino...", 96. Una indicación temporal análoga a la del pasaje de transición ("y en muy pocos dias me mostró jerigonza”) marca el abandono de la técnica escénica. Lo que la sustituye no será ya un resumen - no volverá a haber discurso sumario en todo el tratado, ni tampoco en los dos siguientes-, sino un extenso relato iterativo-durativo. Toda la parte que sigue será, en efecto, una visión global y generalizadora de ese tiempo indefinido, nunca precisado, que Lázaro pasa con el ciego. Antes de entrar de lleno en el reiato iterativo se presenta nuevamente el narrador, comentando por adelantado - pero retrospectivamente- la importancia del ciego en su vida; se dirige a Vuestra Merced y vuelve a explicarle -ya lo había hecho en el Prólogo- la lección que deberá sacarse de su autobiografía ("cuánta virtud sea saber los hombres subir siendo bajos", 97). Se abre así una brecha entre la escena inicial y el relato iterativo. A la vez se recuerda al lector la existencia de ese narrador ( $y$ de su destinatario), el cual va a quedar flotando por encima de su relato, como una presencia a ratos visible, a ratos oculta ${ }^{15}$.

"Pues tornando al bueno de mi ciego y contando sus cosas, Vuestra Merced sepa que desde que Dios crió el mundo, ninguno formó más astuto ni sagaz" (97): así se entra definitivamente en el relato iterativo. Por él sabremos cómo es el ciego y lo que hace, cómo actúa Lázaro y finalmente cómo se deteriora la relación entre

1.4 Para la escenita de "imadre, coco!", cf. infra, nota 18. Emplearé aquí indistintamente los términos escena y relato escénico, puesto que en el episodio del ciego este tipo de relato se manifiesta siempre en forma de escenas redondeadas.

15 Narrador y destinatario reaparecen en la frase que cito a continuación y nuevamente veintiún líneas más abajo ("Mas también quiero que sepa Vuestra Merced que... jamás tan avariento ni mezquino hombre no vi", 98, afirmación enfática que será desmentida al comienzo del Tratado II, puesto que, comparado con el clérigo, el ciego resulta ser "un Alejandre Magno", 113). Cf. nota 31. 
los dos. Toda esta materia se organiza por medio de esa "especie de clasificación paradigmática" de que habla Genette, estableciendo la siguiente serie de conjuntos temáticos, que se van alineando, uno tras otro, en el texto:

1) Cómo era y cómo actuaba el ciego: "En su oficio era un águila. Ciento y tantas oraciones sabía de coro; un tono bajo, reposado y muy sonable, que hacía resonar la iglesia...; un rostro humilde y devoto, que... ponía cuando rezaba...". "Decía saber oraciones para muchos y diversos efectos... Echaba pronósticos a las preñadas... Andábase todo el mundo tras él, especialmente mujeres..." (97-98).

2) La avaricia del ciego y las primeras tretas de Lázaro: “. . .me mataba a mí de hambre..., mas... [yo] le hacía burlas endiabladas... Sangraba el avariento fardel... Todo lo que podía sisar y hurtar traía en medias blancas..." (98-99).

3) Lázaro roba vino al ciego: "Usaba poner cabe sí un jarrillo de vino... y yo... le asía y daba un par de besos callados... [El ciego se da cuenta y] nunca después desamparaba el jarro... Yo, con una paja larga... chupando el vino lo dejaba a buenas noches. . [Descubierto el truco, Lázaro hace un agujero en el jarro, lo tapa con cera y] fingendo haber frío, entrábame entre las piernas del triste ciego... y. .. derretida la cera... comenzaba la fuentecilla a destilarme en la boca... Espantábase, maldecíase, daba al diablo el jarro y el vino..." (99-100). [Sigue la escena del jarrazo, que comentaré en seguida, y sus consecuencias]:

4) Lázaro y el ciego, enemigos: "... Y aunque yo quisiera... perdonalle ei jarrazo, no daba lugar el maltratamiento que... me hacía... Y si alguno le decía por qué me trataba tan mal, luego contaba ei cuento del jarro... y reían mucho... Y en esto, yo siempre le llevaba por los peores caminos... [y él] siempre con el cabo alto del tiento me atentaba el colodrillo... Y aunque yo juraba no lo hacer con malicia, ...no me aprovechaba ni me creía, mas tal era el sentido y el grandísimo entendimiento del traidor" (101-103).

Estos cuatro grupos temáticos son de variable extensión (en el sentido de Genette). Los dos primeros abarcan virtualmente todo el episodio del ciego: debemos suponer que lo que ahí se narra ocurrió desde el momento en que Lázaro y el ciego comienzan su peregrinación hasta el de su violenta separación, y ello a pesar de que el texto no vuelve a mencionar ninguno de esos sucesos. Por su parte, el grupo 4 arranca de un punto específico, situado en un instante, no precisado, de la convivencia de Lázaro con el ciego, el instante en que ocurre el jarrazo (hecho singulativo). Y es que en el grupo 3 el relato, rompiendo con la atemporalidad propia del iterativo, ha presentado los hechos en una secuencia temporal 
(y causal) : los besos al jarro $\rightarrow$ la paja $\rightarrow$ el agujero en el jarro; el paso de una unidad a la otra se hace con un elemento singulativo: "mas turóme poco..." y "pienso que me sintió" (100). Es lo que Genette llama determinación interna (pp. 159-161): dentro de un relato iterativo pueden surgir secciones sucesivas, delimitadas por la mención de hechos singulativos. I a secuencia besospaja-agujero desemboca en una escena (la del jarrazo) ; como después se regresa al relato iterativo, ese incidente constituye un trozo de relato escénico incrustado en medio del pasaje iterativo-durativo.

\section{Del iterativo al Singulativo: LA Escena DEL Jarrazo}

Es curioso observar cómo se pasa aquí de un tipo de relato al otro. El narrador está hablando en el tiempo verbal típico del iterativo: ". . comenzaba la fuentecilla a destilarme en la boca, la cual yo de tal manera ponía, que maldita la gota se perdía. Cuando el pobreto iba a beber, no hallaba nada" (100). Y continúa la narración de lo que -hemos de suponer- ocurrió un sinfín de veces: "Espantábase, maldecíase, ... .no sabiendo qué podía ser. «No diréis, tío, que os lo bebo yo, decía, pues no le quitáis de ia mano»" $(100$ s.). Pese al imperfecto decia, estas palabras del muchacho dan la impresión de haberse pronunciado en una ocasión determinada. $\mathrm{Y}$ de hecho estamos trasladándonos ya a un relato singulativo, pues el texto sigue así: "Tantas vueltas y tientos dio al jarro, que halló la fuente y cayó en la burla..." (101). Viene en seguida la breve escena del jarrazo:

Y luego otro día... sentéme como solía. Estando recibiendo aquellos dulces tragos, mi cara puesta hacia el cielo, un poco cerrados los ojos por mejor gustar el sabroso licor, sintió el desesperado ciego que agora tenía tiempo de tomar de mí venganza, y con toda su fuerza... dejó caer [el jarro] sobre mi boca... Fue tal el golpecillo, que me desatinó y sacó de sentido, y... los pedazos dél se me metieron por la cara... y me quebró los dientes... [Aquí se intercalan dos frases iterativas]. Lavóme con vino las roturas..., y sonriéndose decía: «¿Qué te parece, Lázaro? Lo que te enfermó te sana y da salud»..." (101 s.).

Todavía continúa por un momento el relato singulativo: "Ya que estuve medio bueno... quise yo ahorrar dél; mas no lo hice tan presto por hacello más a mi salvo y provecho". Ahí se reanuda el relato iterativo (nuestro grupo 4): "Y aunque yo quisiera asentar mi corazón y perdonalle el jarrazo, no daba lugar..."

Volvamos al pasaje que precede al relato singulativo. No deja de ser interesante esa manera de narrar, que está a caballo entre 
dos tipos de relato opuestos. Genette, que la ha estudiado de cerca, la bautiza con el nombre de pseudo-iterativo y la describe así: "Escenas presentadas, sobre todo por su redacción en imperfecto, como iterativas, siendo así que, debido a la riqueza y precisión de los detalles, ningún lector puede creer seriamente que se hayan producido y reproducido repetidas veces sin ninguna variación" ${ }^{16}$. Según esta definición, hay varios pasajes de nuestro relato iterativo que podrían considerarse como escenas pseudo-iterativas; pensemos en la minucia con que se narran las sangrías de fardel (98 s.) y sobre todo la treta del "agujero sotil"; ésta funciona como una "pseudo-escena", que se transforma, casi imperceptiblemente, en la escena del jarrazo.

\section{EL ESTILO DIRECTO EN EL RELATO ITERATIVO}

Pero no es sólo la "riqueza y precisión de los detalles" la que puede crear ese tipo intermedio de relato, sino también el uso del estilo directo. Este se ha considerado precisamente como uno de los elementos primordiales de la escena; ahí es donde se logra en mayor medida la ilusión de mimesis $y$, por lo tanto, la de una isocronía entre el tiempo de la historia y el del relato ${ }^{1 \tau}$. Siempre que en un pasaje iterativo del Lazarillo se introduce una frase "hablada" surge la ambivalencia típica del pseudo-iterativo ${ }^{18}$.

16 Genette, p. 152. En seguida añade: "une scène singulière a été comme arbitrairement, et sans aucune modification si ce n'est dans l'emploi des temps, convertie en scène itérative". Es, dice, una "licencia narrativa" antigua (ejemplos: Balzac, Stendhal, Cervantes), "figure de rhétorique narrative, qui n'exige pas d'être prise à la lettre, bien au contraire: le récit affirmant littéralement «ceci se passait tous les jours» pour faire entendre figurément: "tous les jours il se passait quelque chose de ce genre, dont ceci est une réalisation parmi d'autres"'. Quizá el lector no haga, al leer, semejante traducción, sino que se queda con la impresión, consciente o no, de una ambigüedad, que es precisamente la que el autor, a sabiendas o no, ha querido producir. El pseudo-iterativo refleja en el nivel de la técnica narrativa la ambigüedad de contenido que caracteriza al Lazarillo.

17 Cf. Genette, pp. 122 s.; p. 129: “... la scène, le plus souvent «dialoguée..."”; L̈̈MMERT, op. cit., p. 87: la escena "strebt... idealiter nach Zeitdeckung... Die direkte Rede [hat] an ihr allgemeinen grossen Anteil". En cambio Friedman duda: "I am not so sure that... dialogue is the crucial factor" (art. cit., p. 1169).

18 Podemos observarlo ya en la minúscula "escena" del hermanito de Lázaro: "Y acuérdome que estando el negro de mi padrastro treb[e]jando con el mozuelo, como el niño via a mi madre y a mí blancos y a él no, huia dél con miedo para mi madre, y señalando con el dedo decia: "jMadre, coco!» Respondió [!] él riendo: «¡Hideputa!». Yo, aunque bien mochacho, noté aquella palabra de mi hermanico y dije entre mí..." (93-94). El cambio de tiempos verbales no podía ser más sorprendente. Pero no es lo habitual; nor- 
He dicho "siempre", y esto no es del todo cierto. En la parte iterativa que acabamos de analizar hay dos breves "parlamentos" del ciego que no sólo no parecen dichos en un momento dado, sino que, tal como están en el texto, no pudieron haberse pronunciado jamás. Hélos aquí: "Finalmente, nadie le decía padecer alguna pasión, que luego no le decía: «Haced esto, haréis estotro, cosed tal yerba, tomad tal raíz»" (97 s.) ; "Luego él tornaba a dar voces, diciendo: "¿Mandan rezar tal y tal oración?», como suelen decir" (99). Si acaso se puede hablar aquí de estilo directo, sería un estilo directo iterativo. Esos pasajes parecen una miniatura del modo como "hablan" las mujeres del Arcipreste de Talavera, aglomerando en un solo parlamento lo que diez mujeres pudieron haber dicho en otras tantas ocasiones ${ }^{19}$. Por lo demás, no hay nada análogo en todo el resto del Lazarillo.

El uso del estilo directo y una manera pormenorizada de narrar pueden conferir un carácter escénico a ciertos momentos de un relato iterativo; si a aquellos elementos se añaden menciones y descripciones del ámbito en que ocurren los hechos, el efecto escénico es aún mayor. Esto, sin embargo, no ocurre en nuestro texto. $Y$ es extraño: sabemos que la pareja está en continuo movimiento, pero no lo vemos. No hay calles ni casas ni paisaje; apenas una mención genérica de las iglesias donde rezaba el ciego (97) y otra de los caminos, pedregosos y lodosos, por donde lo lleva Lázaro para vengarse del mal trato (103). Al pasar a otra técnica narrativa, después del extenso pasaje iterativo que hemos venido estudiando, ia cosa cambia un poco.

\section{LA ESCENA DE LAS UVAS}

El cambio de técnica se produce después de la frase "tal era el sentido y el grandísimo entendimiento del traidor" (103), que remata el últımo grupo temático del pasaje iterativo. El trozo singulativo que refiere el golpe con el jarro y sus consecuencias inme-

malmente basta la aparición del estilo directo para producir la impresión de ambivalencia aspectual. Podemos aducir el pasaje inicial del relato iterativo: "y como me viese de buen ingenio, holgábase mucho y decía: "Yo oro ni plata no te lo puedo dar..." (97); o el que sigue a la escena del jarrazo: "Y si alguno le decía por qué me trataba tan mal, luego contaba el cuento del jarro, diciendo: "¿Pensaréis que este mi mozo es algún inocente? Pues oíd si el demonio ensayara otra tal hazaña». Santiguándose los que lo oían, decían: "¡Mirá quién pensara de un muchacho tan pequeño tal ruindad!" $Y$ reían mucho el artiticio, y decíanle: "Castigaldo, castigaido, que de Dios lo habréis»" (102 s.). Hay, en el Lazarillo, otros muchos pasajes de este tipo.

10 Un ejemplo: "... "¡Por esta señal de cruz!, ¡Para la virgen Santa María!, ¡Por Dios todopoderoso!, ¡Para los santos de Dios!, ¡Para la pasión de Dios!, ¡Por Dios vivo verdadero!”” (ed. M. Penna, Torino, s.f., p. 103). 
diatas ha sido como un preludio de la técnica escénica que el autor adoptará en el resto del capítulo. Por lo pronto va a lanzar nuevamente al tablado al narrador, junto con su destinatario: "Y porque vea Vuestra Merced a cuánto se estendía el ingenio deste astuto ciego, contaré un caso de muchos que con él me acaescieron, en el cual me paresce dio bien a entender su gran astucia" (103). En seguida, como para separar aún más del relato iterativo anterior la escena que va a contar, da un salto hacia atrás, salto cronológico y espacial que lo lleva al momento y al sitio en que Lázaro inicia su peregrinación con el ciego ("Cuando salimos de Salamanca, su motivo fue venir a tierra de Toledo...", 103) ${ }^{20}$, y proporciona, ahora sí, en un breve pasaje iterativo, ciertas precisiones sobre el movimiento por el espacio: "Y venimos a este camino por los mejores lugares. Donde hallaba buena acogida y ganancia, deteníamonos; donde no, a tercero día hacíamos Sant Juan" (104).

Se inicia el relato singulativo con la mención de una localidad concreta y de una estación del año: "Acaesció que, llegando a un lugar que llaman Almorox al tiempo que cogían las uvas" (104). Estos datos no sitúan realmente la escena dentro del conjunto del relato ni tampoco dentro del tiempo-espacio de la historia (¿ocurrió antes del jarrazo? ¿después de él?). Lo que importa aquí es el hecho mismo de que se concreten las circunstancias; es la señal de que no estamos ya en el ámbito indefinido de lo que ocurrió muchas veces, sino en el muy preciso de un suceso particular. La escena propiamente dicha comienza con un pequeño detalle espacial: "Sentámonos en un valladar"; continúa con un parlamento del ciego bastante más largo que todos los anteriores. Un corto párrafo narra la competencia en torno al racimo, la cual remata en un minúsculo y delicioso pormenor gráfico: "Acabado el racimo, estuvo un poco con el escobajo en la mano, y meneando la cabeza dijo..." (105); y viene en seguida el primer verdadero diálogo de todo el libro, que escenifica, preciosamente, la pointe del cuento de las uvas. El autor ha estrenado aquí una forma más holgada y gozosa de relatar los hechos, a tono con la súbita liberalidad del ciego y con la hermosura misma de la pequeña historia.

\section{LA ESCENA DE LA LONGANIZA}

Una nueva intervención del narrador - "Mas por no ser prolijo, dejo de contar muchas cosas... y quiero decir el despidiente y, con

20 Hay también un salto temático, que nos lleva a la descripción inicial del ciego, donde el narrador (dirigiéndose igualmente a Vuestra Merced) habla de la astucia del ciego: "Vuestra Merced sepa que desde que Dios crió el mundo, ninguno formó más astuto ni sagaz" (97). 
él, acabar" (106) - señala el paso a la siguiente escena. Había que encaminar el texto hacia el final del episodio, hacia la venganza de Lázaro, probablemente prevista desde antes ${ }^{21}$. En cierto modo, el cuento de las uvas había desviado el relato, llevando la relación entre amo y mozo a un terreno casi idílico, de broma inofensiva. La venganza final exigía un retorno a la atmósfera envenenada del odio mutuo, de las agresiones y represalias. El cuento de la longaniza venía muy a propósito.

También esta escena comienza con la mención de un pueblo, a la cual se añade una localización aún más concreta: "Estábamos en Escalona..., en un mesón" (106). Nuevamente se trata de subrayar el carácter individual, único, del suceso. No hay ahora referencia temporal, pero la escena sí queda claramente situada ("determinada") dentro de la temporalidad interna del episodio: es "el despidiente", la última y más atroz rencilla entre amo y mozo, preludio de la venganza que acabará con la relación (y quizá con la vida del ciego).

La escena es mucho más larga que todas las otras. Como si el autor se hubiese engolosinado con la forma de narrar que empleó en la escena de las uvas, se detiene morosamente en las minucias de la acción ("ya que la longaniza había pringado y comídose las pringadas, sacó un maravedí de la bolsa y mandó que fuese por él de vino a la taberna...", 106). La ida a la taberna produce un movimiento desusado: la acción se desdobla y se complica. En la escena de las uvas había dominado el estilo directo sobre el narrativo; aquí es al contrario: casi todo es narración; sólo hay un diálogo, breve como el otro y con su misma organización (habla el ciego, luego Lázaro, luego el ciego). La estructura de la acción es, básicamente, la misma de la escena del jarrazo: Lázaro roba algo (comida-bebida) a su amo; éste lo descubre y se venga brutalmente. Hacia el final se multiplican las coincidencias con el relato (iterativo) que sigue a aquella escena: nuevamente aparece la gente, y el ciego refiere lo ocurrido; hace un comentario burlón, que la gente celebra con risas. Y Lázaro vuelve a su anterior determinación de abandonar al ciego. En las dos escenas el ciego bromea sobre las virtudes curativas del vino; la segunda vez sus palabras adquieren gran relieve: constituyen la famosa profecía ("Yo te digo. .. que si un hombre en el mundo ha de ser bienaventurado con vino, que serás tús", 110), que el narrador va a convertir en tema de su siguiente intervención.

21 Dice Fernando Lázaro, p. 115, que el incidente inicial del toro de piedra "lia sido inventado como preparación de la venganza final, que el autor hallaba ya elaborada como cuento popular y al que destinaba la función de cierre climático del tratado" (subrayo yo). 


\section{LA ESCENA DEL POSTE DE PIEDRA}

En efecto, el narrador vuelve a hacerse visible antes de la última escena, y esta vez con un parlamento de suma importancia, comparable con el que intercala entre la escena inicial y el relato iterativo:

Mas el pronóstico del ciego no salió mentiroso, y después acá muchas veces me acuerdo de aquel hombre, que sin duda debía tener espíritu de profecía, y me pesa de los sinsabores que le hice, aunque bien se lo pagué, considerando lo que aquel día me dijo salirme tan verdadero como adelante Vuestra Merced oirá (110).

Asi juzga en b!oque la conducta de Lázaro con su primer amo y anticipa el último episodio del libro ${ }^{22}$.

La escena de la venganza se inicia, como todas las demás, salvo la del jarrazo, con una referencia espacial, más compleja aquí, y además con una indicación temporal que la sitúa en relación con la escena anterior: "Y fue ansí, que luego otro día salimos por la villa ...y andaba rezando debajo de unos portales que en aquel pueblo había..." (110 s.). Pero no paran aquí las cosas: de pronto tenemos frente a nosotros una escena que, a diferencia de todas las anteriores, está saturada de la conciencia del espacio y del tiempo:

...mas como la noche se venía... díjome...: "Lázaro, esta agua es..., cuanto la noche más cierra, más recia; acojámonos a la posada con tiempo». Para ir allá habíamos de pasar un arroyo... Yo le dije: "...yo veo por donde travesemos más aína...» Dijo: "Llévame a ese lugar..., que agora es invierno...»... Saquéle de bajo de los portales, y llevéle derecho a un pilar o poste de piedra que en la plaza estaba..., y dígole: "Tío, éste es el paso más angosto..." ...Con la priesa que llevábamos de salir del agua... Yo le puse bien derecho enfrente del pilar, y doy un salto y póngome detrás del poste... y díjele: «iSús! Saltá todo lo que podáis, porque deis deste cabo del agua". Aun apenas lo había acabado de decir cuando se abalanza..., tomando un paso atrás... Y tomo la puerta de la villa en los pies de un trote, y antes que la noche viniese di conmigo en Torrijos (111 s.).

¿Cómo explicar este súbito cambio de técnica? ¿Será que la materia misma exigía una intensa intervención del espacio y del tiempo?

2. La trascendencia de esta última intervención del narrador, junto con la configuración del pasaje que relata la venganza de Lázaro, me corrobora en la idea de que el incidente de la longaniza y el del poste de piedra, que en el relato folklórico que los inspiró forman una unidad, constituyen en el Lazarillo, no una escena (como sugieren Claudio Guillén y Fernando Íázaro), sino dos; es importante reconocerlo para comprender la estructura de todo el episodio (cf. infra). 
Mas bien pienso que el autor, antes de pasar al Tratado Segundo, quiso preparar aquí la nueva manera de narrar que en él se inicia ${ }^{23}$. La preparó también introduciendo por primera vez un recurso que luego reaparecerá, intensificado: la heterodoxa alternancia del pretérito y el presente en el relato escénico.

En muchos sentidos, la escena de la venganza constituye algo muy especial dentro de nuestro episodio. El relato se mueve en simétrico vaivén entre el ciego y Lázaro; a cada uno le toca, primero, un pasaje narrativo y luego un parlamento. De esta manera, nunca llega a trabarse un diálogo entre los dos personajes (en el nivel del lenguaje la separación entre ellos es ya un hecho). Al final otra vez acude la gente; sólo que ahora, a diferencia de lo que ocurre al concluir las demás escenas del episodio, ya no hay risa ${ }^{24}$.

\section{Organización de Las escenas}

Es bien conocida la semejanza existente entre el final del episodio y su principio. La muy premeditada coincidencia de los motivos básicos ("calabazada" contra una construcción de piedra, "forma de toro"- "tope de toro") convierte el relato de los dos incidentes, pese a las diferencias de técnica narrativa, en dos escenas paralelas, que enmarcan el resto del episodio ${ }^{25}$. Al analizar desde el punto de vista del manejo del tiempo toda la parte enmarcada por esas dos escenas, pudimos ver que hay un largo pasaje iterativo y tres escenas más. La primera de ellas está incrustrada

23 En el episodio del clérigo, y más aún en el del escudero, marcará rigurosamente el paso del tiempo (por días en el primero, por tajadas de horas en el segundo) y conferirá al espacio un notable relieve.

24 Es curiosa esta coincidencia de los finales: el ciego se rie tras la "cornada" (96), la gente celebra con risas "el artificio" del jarrazo (103), preciosamente "se ríe entre sí" el muchacho cuando el astuto ciego descubre que ha comido las uvas de tres en tres (106), y la risa de los vecinos inunda el mesón cuando el ciego cuenta los "desastres" de su mozo (109) y hace su sarcástica profecía del vino (110). Al terminar el episodio hay gente, pero no risa; según el orden de los rientes ( 1 el ciego, 2 la gente, 3 Lázaro, 4 la gente), a quien le tocaba reírse ahora era al ciego...

25 Cf. Batalllon, op. cit., p. 40. Hay también, en la última escena, una analogía con el pasaje que sigue a la escena inicial: "Comenzamos nuestro camino..., y como me viese de buen ingenio, holgábase mucho y decía: "Yo oro ni plata no te lo puedo dar; mas avisos para vivir, muchos te mostraré" (96 s.): al final el ciego acoge con beneplácito el funesto consejo de saluar "el arroyo": "Parescióle buen consejo, y dijo: "Discreto eres, por esto te quiero bien»" (111). ¿Sería consciente el autor de que Lázaro estaba contestando a aquellos "avisos para vivir" con un consejo para morir? ¿Y habrá una correspondencia deliberada entre "siendo ciego, me alumbró..." (97) y "Dios le cegó aquella hora el entendimiento" (111)? 
en el relato iterativo y las otras dos figuran después de él. Entre la primera, del jarrazo, y la tercera, de la longaniza, hay una serie de analogías temáticas; son también -y no obstante las diferencias en la técnica- escenas paralelas ${ }^{26}$.

¿Y la escena de las uvas? Suele considerársela como un elemento marginal al episodio. María Rosa Lida la juzgó carente de "función estructural”; también para Fernando Lázaro tiene "escasa importancia estructural": "parece traída a este lugar sólo por su belleza"; a su vez, Francisco Rico dice: "nada en [ella] .. parece tener una misión estructural definida; ... no es propiamente miembro vivo en el organismo novelístico" 27 . Sin embargo, es importante reconocer que son $\mathrm{t} r$ es las escenas interiores del episodio, tres escenas asociadas por un tema único -el de las "escaramuzas alimenticias", como las llama Bataillón ${ }^{28}$ - y ya por eso separadas de las dos escenas emnarcadoras, que tratan un tema bien distinto. Este hecho nos lleva a la "ley épica del número tres", cuya importancia en la construcción general del Lazarillo ha descubierto Fernando Lázaro ${ }^{29}$. Las tres escenas están perfectamente organizadas, según un principio estructurador que el autor volvió a utilizar en otras series de tres unidades dentro de su obra: la primera y la tercera se corresponden, la segunda es diferente. Los cuentos del jarrazo y de la longaniza son escenas de enemistad: de robo y venganza; el de las uvas lo es de convivencia, si no pacífica, al menos

26 Hay, a su vez, un curioso paralelismo entre esta pareja de escenas y la otra. En los dos casos la primera escena es mucho más breve; la segunda repite los mismos motivos, pero en forma notablemente ampliada.

$2 \pi$ M. R. Lida de Malkiel, "Función del cuento popular en el Lazarillo de Tormes", CH (1), pp. 349-359 (la cita, p. 353); Fernando LÁZaro, pp. 119 y 118; Francisco Rico, La noziela picaresca y el punto de vista, Barcelona, 1970, pp. 28 s. [abrevio Rico 1970].

28 Op. cit., pp. 22, 23.

29 "Parece no haberse advertido el indicio de que sean tres, justamente, los episodios - los amos- en que el escritor ha aplicado un esfuerzo constructivo mayor" (p. 99). Remite a Axel Olrik y observa que si es "el ciego quien ejercerá un influjo más decisivo sobre Lázaro", esto corresponde a otra ley épica: el primero de los tres elementos es el más importante" (pp. 101 s.). También esta otra ley funciona en nuestras tres escenas, puesto que la del jarrazo, como ha observado el propio Fernando Lázaro (p. 117), tiene "un valor fundamental", al desencadenar el odio, "la gucrra sorda entre los dos" (cf. María Rosa Lida, art. cit., p. 353). Francisco Rico ha reconocido en el episodio "cinco motivos primordiales": [1] calabazada de Lázaro, [2] "las argucias para beberle el vino a su amo y el jarrazo con que las paga", [3] uvas, [4] longaniza, [5] topetazo del ciego (Rico 1970, p. 26). Reconoce asimismo que [1] y [5] "son cara y cruz de una sola moneda" y que [2] y [4] "repiten un mismo esquema". Sólo faltó ver que [3] sí tiene, dentro de ese conjunto, "una misión estructural definida" (y separär en [2], por la diferencia de técnica narrativa, las argucias para robar vino del "jarrazo con que las paga"). 
tranquila: es un descanso en medio de la tensión exacerbada de las otras dos ${ }^{30}$. Éstas son escenas agitadas, dramáticas, en las cuales, además de Lázaro y el ciego, interviene el "personaje colectivo", la gente; en la de las uvas amo y mozo están solos y están inmóviles, sentados en un valladar.

La ley de tres no sólo se da, pues, en la estructura global del libro, sino también en la composición interna de nuestro episodio. $\mathrm{Y}$ aun podemos descubrirla en unidades menores: son tres las "burlas endiabladas" que Lázaro acostumbra hacer al ciego (en el relato iterativo) : 1) la sangría del fardel, 2) el acto de prestidigitación con las monedas, 3) el robo de vino. Esta última burla tiene a su vez tres modalidades sucesivas: 1) los "besos callados", 2) la "paja larga de centeno", 3) la "fuentecilla y agujero sotil".

\section{LA PRESENCIA DEL NARRADOR, ELEMENTO ESTRUCTURANTE}

Si al analizar cómo funciona el tiempo (y el no tiempo) en el episodio del ciego se ha podido avanzar algo, según espero, en la comprensión de su organización interna, al buscar la presencia del narrador ha salido a luz otro aspecto interesante de su construcción. Hemos observado que el narrador aparece en un primer plano cada vez que se pasa de un tipo de relato a otro y de una escena a otra: entre la escena inicial y el relato iterativo, entre éste y la escena de las uvas, entre ésta y la de la longaniza, entre ésta y la de la venganza del poste. Tales irrupciones del narrador tienen un claro valor estructurante: operan una y otra vez como un escalón que hay que subir y luego bajar de nuevo para volver a integrarnos al nivel de la historia.

Y quizá porque la reservó aquí para esa función, la presencia del narrador es poco visible en el resto del episodio. Sólo cinco veces la encuentro dentro del pasaje iterativo ${ }^{31}$, que es donde más esperaríamos verla, y tres veces al comienzo de una escena ${ }^{32}$. Pero

30 María Rosa Lida había hablado del "ritmo mucho más lento" de la escena (art. cit., p. 353), y Fernando Lázaro, de un "remanso de ingenio" (p. 120), del sosiego que la escena introduce "en el ritmo del relato" ( $y$ de "variación inteligente en la naturaleza de las tretas") (p. 119).

31 Además de la alocución a Vuestra Merced citada en la nota 15 (con la cual el narrador parece querer separar los grupos temáticos 1 y 2; cf. supra, p. 206), hay tres intervenciones en la parte inicial del relato iterativo: "Déstas sacaba él grandes provechos con las artes que digo", "Digo verdad: si con mi sotileza... no me supiera remediar...", "le hacía burlas endiabladas, de las cuales contaré algunas" (98); más adelante: "como fuese el traidor tan astuto, pienso que me sintió" (100).

$32 \mathrm{La}$ del toro de piedra (cf. supra, p. 204); la de las uvas ("Y como suelen ir los cestos maltratados $\mathrm{y} .$. la uva en aquel tiempo estí muy ma- 
hay un momento excepcional en que el narrador irrumpe en el escenario cuando menos lo pensamos e irrumpe además desempeñando un papel que no le corresponde. Se trata de la escena del jarrazo, en el instante mismo del golpe:

...con toda su fuerza, alzando con dos manos aquel dulce y amargo jarro, le dejó caer sobre mi boca, ayudándose, como digo, con todo su poder, de manera que el pobre Lázaro, que de nada desto se guardaba, antes, como otras veces, estaba descuidado y gozoso, verdaderamente me pareció que el cielo, con todo lo que en él hay, me había caído encima (101).

El pasaje es interesantísimo. En el momento más dramático del relato, el Lázaro narrador se entrega con tal intensidad a la evocación, aue se olvida de sí mismo e invade el texto, hablando, con su voz de narrador, del Lázaro protagonista, como de una tercera persona. Se crea así una distancia, entre humorística y trágica ${ }^{\mathbf{3 3}}$, y se percibe el desmayo de Lázaro como una verdadera ausencia suya, ausencia instantánea, pues en seguida se recupera, con un violento anacoluto, la ley del relato autobiográfico.

\section{EL NARRADOR OMNISCIENTE}

En todo ese pasaje, desde el momento en que el ciego descubre el agujero tapado con cera, nos las tenemos que haber con un narrador omnisciente, que habla de lo que su yo protagonista no pudo presenciar. El ciego ha disimulado: Lázaro no sospecha para nada que ha sido descubierto; está feliz, "recibiendo aquellos dulces tragos..." (101). Sólo un narrador omnisciente podía saber que en ese preciso instante "sintió el desesperado ciego que agora tenía tiempo de tomar... venganza" y que "alzando con dos manos aquel. . jarro, le dejó caer. .."

El autor del Lazarillo sabía muy bien que debía limitar el punto de vista de su relato al del narrador (o sea, relatar sólo lo que éste vio, pensó o supuso), y de vez en cuando lo vemos tomando precauciones para no romper esa ilusión. Así, después de contar cómo Lázaro chupaba el vino con la paja, dice: "pienso que me

dura...", 104); la de la longaniza ("Púsome el demonio el aparejo delante de los ojos, el cual, como suelen decir, hace al ladrón", 106). En los tres casos se trata de un "presente del narrador" que no implica una presencia muy notable.

33 Cf. Frank Durand, "The author and Lazaro: leveis of comic meaning", BHS, 45 (1968), p. 95: "The focal point of this passage changes...: the interest in Lazarillo as subject shifts to Lazarillo as story-teller, enjoying his art... To achieve this enjoyment the author momentarily separates himself from the subject by using the third person..." 
sintió" (100), y después del robo de la longaniza: "y llegóse a olerme, y como debió sentir el huelgo" (107 s.) ${ }^{34}$. Pero por otra parte, no es nada raro que el narrador se meta despreocupadamente en la cabeza, ya no de Lázaro, sino de los demás personajes: "un ciego, el cual, paresciéndole que yo sería para adestralle..." (95) ; "y como sintió que [yo] tenía la cabeza par de la piedra" (96) ; "se descuidaba, pensando que yo estaba entendiendo en otras cosas" (98); "en los tragos conocia [él] la falta" (100); "Acordó de hacer un banquete... por contentarme" (104), etc. Podría argüirse que todas éstas son cosas que el narrador supone; pero, al no presentarlas como conjeturas, asume automáticamente el papel de narrador omnisciente.

La escena del jarrazo constituye el caso más flagrante de omnisciencia del narrador, puesto que éste no sólo relata lo que el ciego siente, sino también lo que hace cuando Lázaro no puede verlo. Pero no es el único caso así. En la página 107 cuenta el narrador que Lázaro regresa con el vino, y: "hallé al pecador del ciego que tenía entre dos rebanadas apretado el nabo, al cual aún no había conoscido, por no lo haber tentado con la mano" (107) ¿ ¿Cómo lo supo, si Lázaro no estaba ahí? En el resto del libro hay por lo menos otros dos pasajes análogos ${ }^{35}$. ¿Descuidos? ¿Travesuras del autor?

Por todo lo que hemos visto, el autor sabía muy bien lo que hacía. Inventó a un narrador y le cedió la palabra; lo dejó intervenir en el relato con su propia personalidad de hombre y de escritor y aun le permitió excederse de vez en cuando en sus atribuciones. Sin embargo, no le dio poderes absolutos: se reservó la posibilidad de utilizarlo para sus propios fines de escritor, poniéndolo en escena cuando convenía a la configuración del relato y haciéndolo invisible cada vez que su presencia pudiera dificultar la necesaria intimidad entre el libro y el lector.

Decía Claudio Guillén que "el principal propósito del autor [del narrador] no consiste, al parecer, en narrar -en contar sucesos dignos de ser contados, y por decirlo así, autónomos-, sino en incorporar estos sucesos a su propia persona"; "lo narrado queda referido al ser del narrador..., el pasado está supeditado al pre-

34 Cf. también, en II, 120: "sin dubda creyó ser ratones"; III, 141: "Quiso Dios cumplir mi deseo y aun pienso que el suyo"; III, 146: "una que hebia ser su mujer del difunto"; V, 163: "... algunos que allí estaban, y a mi parescer no sin harto temor, se llegaron y le trabaron de los brazos".

35 Pienso que exagera mi amigo Francisco Rico cuando dice que en el Lazarillo "el artificio autobiográfico... no ofrece una sola falla" e insiste en la coherencia del "punto de vista que informa todo el libro": Rico 1967, p. lxvi, y 1970, pp. 38 s. 
sente" 3i. Cuando contemplamos en su conjunto esa autobiografía ficticia y buscamos su sentido, podemos, en efecto, llegar a la conclusión de que al narrador no le interesa "lo pretérito como tal, lo transcurrido como algo divisible del presente..." 37 .

Y sin embargo, el t e x t o mismo de la obra nos abre un panorama más complejo del que esta interpretación permitiría suponer. Porque la visión de la historia que tiene el narrador, el Lázaro "maduro y desengañado", no constituye más que uno de los estratos de nuestro texto, el estrato que vemos cuando el narrador, pasando a un primer plano, mediatiza con sus intervenciones el relato de las cosas pasadas. Pero una buena parte de la obra se desarrolla en un nivel distinto, en el cual las cosas pasadas funcionan para nosotros, lectores, como cosas presentes, en los dos sentidos de la palabra. Los relatos escénicos llegan a crear tal ilusión de realidad, que creemos presenciar los hechos, sin mediación alguna, como si los viéramos suceder. En cuanto al relato iterativo de nuestro episodio, recordemos que las intervenciones del narrador se acumulan, casi todas, al principio (cf. nota 31), en la primera página; y ya ahí, con la evocación del fardel, el autor empieza a encariñarse con un tipo de relato que abunda en diminutos detalles gráficos, los cuales nos ponen las cosas directamente delante de los ojos. $Y$ ese tipo de relato es el que domina en el episodio del ciego.

"Lázaro, más que Lazarillo, es el centro de gravedad de la obra" dice Guillén (p. 271). Quizás lo sea, pero sólo cuando cerramos el libro y nos quedamos pensando. El libro abierto no nos permite tal abstracción; ahí está el muchacho Lazarillo, atrayéndonos, sumergiéndonos en el mundo de las cosas que él vive, piensa, siente; presencia verdadera, que el otro Lázaro no puede -ni quiere- suplantar.

Margit Frenk Alatorre

E1 Colegio de México.

36 Art. cit., pp. 270 s. A su vez, Francisco Rico habla de "la convergencia de todo lo pasado en el ser presente del pregonero que cuenta su vida" (Rrco 1967, pp. xliii s.) y en su excelente estudio de 1970 dice, p. 29: "el pasado de Lázaro se tamiza en la novela con el cedazo de su presente".

B7 Gulluḱn, art. cit., p. 271. 